\title{
Nutrition in the media: A cross-sectional analysis of health and nutrition articles reported in five popular UK newspapers
}

\author{
Nafeesa Jamil and CEL Evans \\ Nutritional Epidemiology Group, School of Food Science and Nutrition, University of Leeds, Leeds UK
}

Non-communicable diseases (NCDS) are the leading cause of death in the UK accounting for $89 \%$ of total deaths in the UK ${ }^{(1)}$. Obesity, diabetes, cardiovascular disease (CVD) and respiratory disease are known as the major four chronic diseases, which account for the most cases of mortality and morbidity in the $\mathrm{UK}^{(2)}$. Therefore promoting public health is a vital role for the Government.News media is the primary source for health related information to the public ${ }^{(3)}$, providing information through the Internet, smartphones, radio stations and printed newspapers ${ }^{(4)}$. Despite the decline in circulation of newspapers including 'tabloids' and 'broadsheets', it remains the most efficient source to provide the public with essential information ${ }^{(5)}$, however nutrition information is not always accurate and fully informative.

This study analyses articles from five of the most popular newspapers in the UK collected over 6 weeks from the $30^{\text {th }}$ of June to the $9^{\text {th }}$ of August 2014. Descriptive analysis was carried out and all articles which reported health and nutrition topics were graded using a validated quality assessment tool ${ }^{(6)}$. Four tabloids and one broadsheet was used to analyse articles.

143 articles were identified and assessed providing a total of 3.4 articles on average related to health and nutrition being published each day across all 5 papers. Data was checked in duplicate. Table 1 shows a summary of the mean article score for each newspaper. Results showed that The Daily Express and the Daily Telegraph published articles of a higher quality. Articles in The Sun had the lowest scores and therefore published poor quality articles. Articles that provided more scientific background, were written by a named journalist, often with health experience and were larger in length resulted in statistically higher scores.

Table 1. Summary of the descriptive analysis, by newspaper.

\begin{tabular}{|c|c|c|c|c|c|c|c|c|}
\hline \multirow[b]{2}{*}{ Newspaper } & \multirow{2}{*}{$\begin{array}{l}\text { Number of } \\
\text { published articles }\end{array}$} & \multicolumn{3}{|l|}{ Size } & \multirow{2}{*}{$\begin{array}{l}\text { Author } \\
\text { listed (\%) }\end{array}$} & \multicolumn{3}{|c|}{ Quality Assessment Instrument score } \\
\hline & & Small $(\%)$ & Medium (\%) & Large $(\%)$ & & Mean & SD & CI $(95 \%)$ \\
\hline The Sun & 20 & 80 & 10 & 10 & 40 & -1.25 & $3 \cdot 62$ & $-2.95-0.45$ \\
\hline Daily Mirror & 23 & 48 & 4 & 48 & 76 & 1.60 & $3 \cdot 03$ & $-0 \cdot 13-3 \cdot 35$ \\
\hline Daily Mail & 43 & 65 & 19 & 16 & 67 & 1.65 & $4 \cdot 21$ & $0 \cdot 35-2 \cdot 95$ \\
\hline Daily Express & 29 & 48 & 24 & 28 & 79 & $3 \cdot 96$ & 3.98 & $2 \cdot 45-5 \cdot 48$ \\
\hline The Daily Telegraph & 28 & 79 & 18 & 4 & 71 & $2 \cdot 78$ & $4 \cdot 29$ & $1 \cdot 12-4.45$ \\
\hline Total & 143 & 64 & 16 & 20 & 68 & 1.93 & $4 \cdot 32$ & $1.22-2.68$ \\
\hline
\end{tabular}

SD - Standard Deviation CI - Confidence Interval

These results indicate that the quality of nutrition and health articles varies substantially. To improve the quality of articles more training is needed for journalists to ensure that they understand the scientific study and provide sufficient information but is still appropriate.

1. Cowan M. United Kingdom Country Profile. [Online]. [Accessed 21/08/2015]. Available from: http://www.who.int/chp/countries/en/. 2014.

2. WHO. Non-communicable diseases. [Online]. [Accessed 21/08/2015]. Available from: http://www.who.int/mediacentre/factsheets/fs $355 /$ en/.2015.

3. Stryker J.E. Reporting Medical Information: Effects of Press Releases and Newsworthiness on Medical Journal Articles' Visibility in the News Media. Preventive Medicine.2002:35(5), pp. 519-530.

4. Cooper B.E. et al. The quality of the evidence for dietary advice given in UK national newspapers. Public Understanding of Science. 21(6), pp. 664-673. 2012.

5. OECD. The evolution of news and the internet. Paris: Organisation for Economic Co-operation and Development. 2010.

6. Robinson A. et al. 2013. Analysis of health stories in daily newspapers in the UK. Public Health. 127(1), pp. 39-45. 